- La flora Australiana presenta una enorme diversidad y atractivo para ser usadas como especies ornamentales, muchas de las cuales son originarias de situaciones mediterráneas o templadas.

- Estudios realizados tanto en Australia como en otros países indican una tendencia al aumento de la demanda por esta flora en mercados tales como Norteamérica, Europa y Asia.

- Existe un número importante de nuevas especies de origen australiano que ya son cultivadas comercialmente en la zona del secano costero de Chile central, con buenas proyecciones para el mercado de exportación.
- Es necesario realizar estudios para evaluar la adaptabilidad y el resultado económico de estas especies en ésta y otras áreas de nuestro país.

\section{BIBLIOGRAFÍA}

ELLIOT, W.R; JONES D.L. 1990. Encyclopaedia of Australian Plants. Melbourne, Australia, Lothian Publishing. $500 \mathrm{p}$ (each volume)

MATTHEWS, L.J. 2002. The Protea Book. Christchurch, New Zealand. Cup Canterbury University Press 184p.

WRIGLEY, J.W.; FAGG, M. 1991. Banksias, Waratahs and Grevilleas. Sidney, Australia Angus and Robertson Publishers Pty. 584 p.

\title{
ESTUDIO, MULTIPLICACIÓN Y MANEJO DE ESPECIES NATIVAS CON APTITUD ORNAMENTAL, PRESENTES EN LA FLORA PATAGÓNICA DE LA REGIÓN DE AYSÉN
}

\section{STUDY, MULTIPLICATION AND HANDLING OF NATIVE SPECIES WITH ORNAMENTAL APTITUDE OF THE PATAGONIAN FLORA, AYSEN REGION, CHILE}

\author{
Manzano E. '; Mansilla A. '; Seemann P. ${ }^{2}$; Schiappacasse F. ${ }^{3}$; Musalem M. ${ }^{4}$; Riedemann P. \\ 'Centro Trapananda, Universidad Austral de Chile, Portales 73, Coyhaique. e-mail: emanzano@uach.cl \\ ${ }^{2}$ Facultad de Ciencias Agrarias, Universidad Austral de Chile, Casilla 567, Valdivia. \\ ${ }^{3}$ Facultad de Ciencias Agrarias, Universidad de Talca, Casilla 747, Talca. \\ ${ }^{4}$ Vivero Pumahuida, Carretera San Martín 7021, Santiago. \\ ${ }^{5}$ Senegal Norte 2527, Santiago
}

La flora nativa de Chile posee una gran riqueza en cuanto a diversidad genética, sin que se logre aún evidenciar una valorización social relevante de la importancia y utilización directa de este recurso. La falta de estudios prolongados y profundos de la biología de estas especies ha limitado su conocimiento específico $\mathrm{y}$, en consecuencia, ha retrasado el proceso de domesticación de un sin número de especies nativas que, hoy en día, representan una fuente importante de recursos económicos en países extranjeros.

Nuestro país se caracteriza por presentar una flora de gran belleza, atractivo y adaptabilidad de sus flores y follajes, que podrían ser usadas con éxito en el diseño de áreas verdes. Esto coincide con el creciente interés por el uso de flora nativa para la ornamentación de jardines y espacios públicos, pero contrasta con el hecho de que las especies ornamentales de mayor utilización aún provienen del extranjero. Por otro lado, Chile exporta follaje decorativo principalmente helechos y árboles del bosque nativo del sur de Chile, los que son recolectados directamente de su hábitat causando daño al ambiente natural. De allí la necesidad de investigar acerca de su propagación con el fin de evitar que se extraigan de manera indiscriminada y de generar nuevas alternativas de producción. Creemos que algunas 
de estas plantas constituyen un recurso genético que debe ser utilizado con cuidado; más aún debemos evitar que el interés que despiertan lleve a la pérdida de poblaciones naturales.

La Región de Aysén actualmente cuenta con un potencial de flora nativa que hasta la fecha ha sido poco estudiado y, aún menos desarrollado en el ámbito de la floricultura a escala comercial. De acuerdo a antecedentes bibliográficos regionales y nacionales sobre la flora de la Región de Aysén, es posible encontrar aproximadamente 281 taxa de flora silvestre dentro de sus límites administrativos. Estas especies o subespecies están agrupadas en 169 géneros, 76 familias y 51 ordenes. La presencia y distribución de la flora regional está plenamente marcada por las características físicas de Aysén, fundamentalmente las edafoclimáticas, que han condicionado la existencia, frecuencia y desarrollo de las especies de flora, así como también su forma.

Entre los años 2001 y 2004, el Centro Trapananda de la Universidad Austral de Chile en Coyhaique desarrolló un proyecto que tuvo por objetivo estudiar, multiplicar y manejar especies de la flora nativa de la XI Región. Se trabajó con diez especies nativas que fueron recolectadas de su ambiente natural durante el crecimiento activo y receso de las plantas; fueron identificadas taxonómicamente y se estudió su morfología, fenología y aspectos reproductivos. Se estudió diversos métodos de propagación tales como estaquillado, división y separación de plantas, y semillas. Todo esto con la finalidad de obtener material homogéneo para establecer las primeras aproximaciones hacia un cultivo agronómico. A partir de los antecedentes obtenidos se elaboró fichas técnicas de manejo de las especies.

El proyecto tuvo una duración de 36 meses y se utilizó la infraestructura que posee el Centro Trapananda en la ciudad de Coyhaique. Se contó con el cofinanciamiento de la Fundación para la Innovación Agraria (FIA), la colaboración del Liceo Agrícola de la Patagonia (CODESSER) y del Vivero Pumahuida Limitada.

\section{BIBLIOGRAFÍA}

BEWLEY. J.; BLACK, L. 1994. Seed: Physiology of Development and germination. England, Plenum Pub Corp. 445p.

CORREA, M. N. 1988. Flora Patagónica. Parte V. Dicotyledoneas dialipétalas. Colección Científica del Instituto Nacional de Tecnología Agropecuaria, Buenos Aires. Argentina. 390p.

RODRÍGUEZ, G.; MALDONADO, C. 1997. Arbustos nativos de Chile. Métodos de propagación. Concepción, Universidad de Concepción. 99p.

Cuadro 1. Listado de especies nativas presente en la XI región con potencial ornamental utilizadas en el estudio.

Table 1. List of native species present in the XI Region with ornamental potential, used in the study.

\begin{tabular}{|c|c|c|c|c|c|c|c|}
\hline \multirow{2}{*}{$\begin{array}{l}\text { Nombre } \\
\text { cientifico }\end{array}$} & \multirow{2}{*}{$\begin{array}{l}\text { Nombre } \\
\text { común }\end{array}$} & \multirow[t]{2}{*}{ Familia } & \multirow[t]{2}{*}{ Hábito } & \multicolumn{4}{|c|}{ Potencial uso ornamental } \\
\hline & & & & $\begin{array}{l}\text { Jar. } \\
\text { din }\end{array}$ & Maceta & Flor de corte & Otros \\
\hline $\begin{array}{l}\text { Alstroemeria } \\
\text { patagonica }\end{array}$ & $\begin{array}{c}\text { Mariposa } \\
\text { patagónica }\end{array}$ & Amaryllidaceae & Herbácea & $x$ & $x$ & & $\begin{array}{c}\text { Mejoramiento } \\
\text { genético de } \\
\text { especies } \\
\text { cultivadas }\end{array}$ \\
\hline $\begin{array}{l}\text { Anemone } \\
\text { multifida }\end{array}$ & Anémona & Ranunculaceae & Herbácea & $x$ & $x$ & $x$ & \\
\hline $\begin{array}{l}\text { Berberis } \\
\text { serrato-dentata }\end{array}$ & $\begin{array}{c}\text { Michai del } \\
\text { bosque }\end{array}$ & Berberidaceae & Arbustiva & $x$ & & & $\begin{array}{l}\text { Utilización frutos } \\
\text { comestibles }\end{array}$ \\
\hline $\begin{array}{l}\text { Calceolaria } \\
\text { uniflora }\end{array}$ & $\begin{array}{c}\text { Zapatito de la } \\
\text { virgen }\end{array}$ & Scrophulariaceae & Herbácea & $x$ & $x$ & & $\begin{array}{l}\text { Turismo de } \\
\text { observación }\end{array}$ \\
\hline Escallonia virgata & $\begin{array}{c}\text { Meki, chapel, } \\
\text { mata negra }\end{array}$ & Escaloniáceas & Arbustiva & $x$ & & $\begin{array}{c}\text { Follaje } \\
\text { decorativo }\end{array}$ & \\
\hline $\begin{array}{l}\text { Gaultheria } \\
\text { mucronata }\end{array}$ & Chaura & Ericaceae & Arbustiva & $x$ & $x$ & & $\begin{array}{l}\text { Utilización frutos } \\
\text { comestibles }\end{array}$ \\
\hline $\begin{array}{l}\text { Gunnera } \\
\text { magellanica }\end{array}$ & $\begin{array}{l}\text { Nalca enana } \\
\text { Pangue chico }\end{array}$ & Gunneraceae & Herbácea & $x$ & $x$ & & $\begin{array}{l}\text { Manejo de } \\
\text { taludes }\end{array}$ \\
\hline Mutisia decurrren & $\begin{array}{l}\text { Clavel de } \\
\text { campo }\end{array}$ & Compositae & $\begin{array}{l}\text { Herbácea } \\
\text { Trepadora }\end{array}$ & $x$ & $x$ & & \\
\hline $\begin{array}{l}\text { Philesia } \\
\text { magellanica }\end{array}$ & $\begin{array}{l}\text { Coicopihue, } \\
\text { copihuelo }\end{array}$ & Philesiaceae & Trepadora & $x$ & $x$ & & \\
\hline Sisyrinchium spp & $\begin{array}{c}\text { Ñuño, lirio de } \\
\text { campo }\end{array}$ & Iridaceae & Herbácea & $x$ & $x$ & $x$ & \\
\hline
\end{tabular}

